\title{
Improvement of Laser Transmission Welding of Glass with Titanium Alloy by Laser Surface Treatment
}

\author{
Pin $\mathrm{Li}^{1,2}$, Xingwen $\mathrm{Xu}^{2}$, Wensheng Tan ${ }^{3}$, Huixia Liu ${ }^{2, *}$ and Xiao Wang ${ }^{2}$ \\ 1 School of Mechanical Engineering, Shanghai Jiaotong University, Shanghai 200000, China; \\ lipsjtu@sjtu.edu.cn or lip@ujs.edu.cn \\ 2 School of Mechanical Engineering, Jiangsu University, Zhenjiang 212013, China; \\ 18852860868@163.com (X.X.); wx@ujs.edu.cn (X.W.) \\ 3 Changzhou Key Laboratory of Large Plastic Parts Intelligence Manufacturing, Changzhou College of \\ Information Technology, Changzhou 213164, China; tws.163@163.com \\ * Correspondence: lhx@ujs.edu.cn; Tel.: +86-511-8879-7998; Fax: +86-511-8878-0276
}

Received: 13 September 2018; Accepted: 19 October 2018; Published: 22 October 2018

\begin{abstract}
Laser surface treatment of the titanium alloy was locally oxidized on the metal surface to improve the joint strength of laser transmission welding of high borosilicate glass with titanium alloy. The results find that the welding strength was increased 5 times. The welding mechanism was investigated by the morphology of the welded parts, the tensile-fracture failure mode, the diffusion of the interface elements, and the surface free energy. The results show that there are many adherents between the titanium alloy and high borosilicate glass after tensile fracture, the welding strength was higher when the laser voltage was $460 \mathrm{~V}$, and the tensile-fracture failure mode is mainly ductile fracture. Element-line scanning analysis revealed that elemental diffusion occurred in the two materials, which is an important reason for the high welding strength. Surface free-energy analysis shows that laser surface treatment improves the surface free energy of titanium alloy, promotes the wettability and compatibility, and increases the welding strength of titanium alloy with glass.
\end{abstract}

Keywords: laser transmission welding; laser surface treatment; titanium alloy; high borosilicate glass; surface free energy; elemental diffusion

\section{Introduction}

Glass to metal seals are widely employed in lighting and electronic devices, automotive, and medical fields [1]. The glass to metal seal is traditional a fusion technique with the glass melted in contact with metal parts to be sealed to. Matched thermal expansion seals, unmatched expansion seals, soldered seals, and mechanical joints are the four major sealing methods of glass to metal [2]. Recently, high-frequency induction heating is used to seal the glass to the Kovar in solar receiver tubes and developed a highly automated process [3]. Due to the nonlinear absorption characteristics of ultrashort-pulsed lasers, ultrashort lasers have attracted significant attention for their application in the fields of cutting [4] and surface mechanical characterization [5]. Laser welding is considered to be a highly-flexible technique with potential for joining glasses and metals. Carter et al. reported systematic analysis and comparison of picosecond laser microwelding of industry relevant A16082 parts to $\mathrm{SiO}_{2}$ and $\mathrm{BK} 7$ [6]. Volpe et al. reported on femtosecond laser microwelding of two transparent layers of polymethyl methacrylate (PMMA) based on nonlinear absorption and localized heat accumulation at high repetition rates [7]. For laser transmission welding of glass and metals [8], the laser transmission welding of copper substrates with borosilicate glass was achieved using a femtosecond laser by Itoh et al. Although the melting point and thermal-expansion coefficient of these two materials are quite different, a relatively reliable connection was formed between the two materials [9]. Utsumi reported a 
direct welding of copper balls with borosilicate glass using a short-pulsed laser [10]. Quintino et al. used a femtosecond laser with a pulse width of $35 \mathrm{fs}$ for laser transmission welding of glass flakes with NiTi alloy flakes. It has been shown that the NiTi particles were formed and splashed in a direction perpendicular to the laser propagation after the laser pulses impacted on the surface. A dimple structure was observed at the weld, indicating a good connection between the two materials [11]. Flury successfully prepared metal lattices on a glass substrate using a glass surface coating to induce reverse transfer by a femtosecond laser [12]. Ciuca et al. used a picosecond laser to achieve transmission welding between quartz glass and aluminum, and found that the nanocrystalline silicon, $\gamma-\mathrm{Al}_{2} \mathrm{O}_{3}$, and $\delta-\mathrm{Al}_{2} \mathrm{O}_{3}$ were formed in the weld zone [13]. Carter et al. used a picosecond laser to weld a variety of metals such as aluminum, copper, and stainless steel with glass, and found that cracks existed at the interface between metal and glass [14].

The high price of ultrashort-pulsed lasers makes them impractical for application in laser transmission welding technology for welding between metal and glass. Lin et al. used a relatively inexpensive long-pulsed fiber laser to achieve the welding of quartz and anodized aluminum [15]. Wetting is very important to enhance the thermo-mechanical properties in the manufacture of metal matrix composite materials, and reactive infiltration. Narciso et al. enhanced interfacial thermal conductivity in Al/Diamond composites by diamond surface modification [16], and studied the porosity effect on thermal properties of Al-12 wt \% Si/Graphite composties [17]. In addition, to improve the strength and hermeticity of the joints, the pre-oxidation was used to form an oxide film on the metal surface. Chern et al. improved the wettability and tightness of 7056 glass on a Kovar surface by pre-oxidizing the surface of Kovar alloy using a furnace thermal treatment [18]. Zhang et al. improved the wettability and diffusivity of borosilicate glass on the surface of Kovar alloy by laser melting oxidation of metal surfaces [19]. Li et al. improved the joint strength of PS and titanium using the two pretreatment methods (laser oxidization treatment and oxygen plasma surface treatment) [20]. Moreover, the laser surface treatment does not require pre-oxidation, and heat preservation of the entire part and the local oxidation of the metal surface can be quickly achieved with good selectivity and repeatability.

The welding of titanium alloy with high borosilicate glass was investigated in this study; it was found that the welding strength of high borosilicate glass with titanium alloy without surface oxidation was very low. To improve the joint strength, the surface of the titanium alloy was first locally oxidized using a semiconductor laser, and transmission welding of titanium alloy with borosilicate glass was then conducted using a long-pulsed Nd:YAG laser. The influence of laser surface treatment on the welding strength of laser transmission welding and the welding mechanism of titanium alloy with high borosilicate glass were studied by analyzing the microstructure, the tensile-fracture failure mode of the weld, the interface elemental diffusion, and the surface free energy.

\section{Materials and Methods}

The main properties of the used materials are shown in Tables 1-3. The size of the titanium alloy and the high borosilicate glass samples used in this study was $50 \mathrm{~mm} \times 20 \mathrm{~mm} \times 2 \mathrm{~mm}$. Before beginning the experiment, the samples were cleaned with alcohol in an ultrasonic cleaner and dried in a dry box for $12 \mathrm{~h}$ to remove impurities from the material's surface.

Table 1. Main properties of titanium alloy and high borosilicate glass.

\begin{tabular}{ccc}
\hline Property & Titanium Alloy & High Borosilicate Glass \\
\hline Density $\left(\mathrm{g} / \mathrm{cm}^{3}\right)$ & 4.5 & 2.23 \\
Specific heat J/ $(\mathrm{kg} \mathrm{K})$ & 520 & 98 \\
Thermal conductivity $(\mathrm{W} / \mathrm{mK})$ & 7.95 & 1.2 \\
Melting temperature, $\mathrm{Tm}\left({ }^{\circ} \mathrm{C}\right)$ & 1660 & 1680 \\
Ultimate tensile stress $(\mathrm{MPa})$ & 895 & $40-100$ \\
\hline
\end{tabular}


Table 2. Content of elements in TC4 titanium alloy.

\begin{tabular}{cc}
\hline Chemical Composition & Mass Percentag \\
\hline $\mathrm{Ti}$ & $\mathrm{Bal}$ \\
$\mathrm{Fe}$ & $\leq 0.3 \%$ \\
$\mathrm{C}$ & $\leq 0.1 \%$ \\
$\mathrm{~N}$ & $\leq 0.05 \%$ \\
$\mathrm{O}$ & $\leq 0.015 \%$ \\
$\mathrm{H}$ & $\leq 0.2 \%$ \\
$\mathrm{~V}$ & $5.5 \sim 6.8 \%$ \\
$\mathrm{Al}$ & $3.5 \sim 4.5 \%$ \\
\hline
\end{tabular}

Table 3. Compositions of high borosilicate glass 3.3.

\begin{tabular}{cc}
\hline Chemical Composition & Mass Percentag \\
\hline $\mathrm{SiO}_{2}$ & $80.4 \%$ \\
$\mathrm{~B}_{2} \mathrm{O}_{3}$ & $12.7 \%$ \\
$\mathrm{Al}_{2} \mathrm{O}_{3}$ & $2.4 \%$ \\
$\mathrm{Na}_{2} \mathrm{O} \& \mathrm{~K}_{2} \mathrm{O}$ & $4.2 \%$ \\
Others & $0.3 \%$ \\
\hline
\end{tabular}

The purpose of laser surface treatment is to form an oxide film on the metal surface. The degree of peroxidation directly influences the strength and hermeticity of the joint. The principle of laser surface treatment is to scan the surface of titanium alloy with a laser under atmospheric conditions, and then the metal is oxygenated by heating to produce a certain thickness of oxide film. A semiconductor laser (Compact 130/140, DILAS Diodenlaser GmbH, Mainz, Germany) was used for laser surface oxidation with an output wavelength of $980 \pm 10 \mathrm{~nm}$, a minimum spot diameter of 700-800 $\mu \mathrm{m}$ with a circular shape, a maximum output power of $130 \mathrm{~W}$, and a working temperature kept between $15-25^{\circ} \mathrm{C}$. The process parameters and limits for laser surface treatment are shown in Table 4.

Table 4. Process parameters and limits for laser surface treatment.

\begin{tabular}{cccc}
\hline Parameter & \multicolumn{3}{c}{ Limits } \\
\hline Laser power for surface treatment $(\mathrm{W})$ & 40 & 50 & 60 \\
Laser scanning speed (mm/s) & 5 & 5 & 5 \\
Number of scans (n) & 8 & 8 & 8 \\
Spot diameter (mm) & 2 & 2 & 2 \\
\hline
\end{tabular}

For the laser transmission welding, a long-pulsed Nd:YAG laser (StarWeld 250, Rofin-Sinar Laser $\mathrm{GmbH}$, Hamburg, Germany) with an output wavelength of $1064 \mathrm{~nm}$ was applied. Figure 1 presents a schematic of the principle of laser transmission welding, and the experiment was performed in the form of the lap-joint configuration [21]. The upper-layer material was made of high borosilicate glass with excellent light transmittance, and the lower layer was made of surface-oxidized titanium alloy as the light-absorbing material. In addition, the $\mathrm{K} 9$ glass was used as the upper and lower clamping layer and a certain clamping pressure of $0.5 \mathrm{MPa}$ was applied. When the laser was irradiated onto the surface of the titanium alloy transmission through the upper high borosilicate glass, the surface of the titanium alloy absorbed energy, so that the temperature at the interface increased sharply, and makes local melting titanium alloy at high temperature. Under the impact of the pulsed laser, the high-temperature titanium alloy droplets were sprayed around, which caused melting and micro-cracking of the glass surface, forming a small-sized interlocking effect. The welding of the titanium alloy with the glass was thus achieved. The process parameters and limits for laser transmission welding are shown in Table 5. Three replicates were performed for each test condition. 


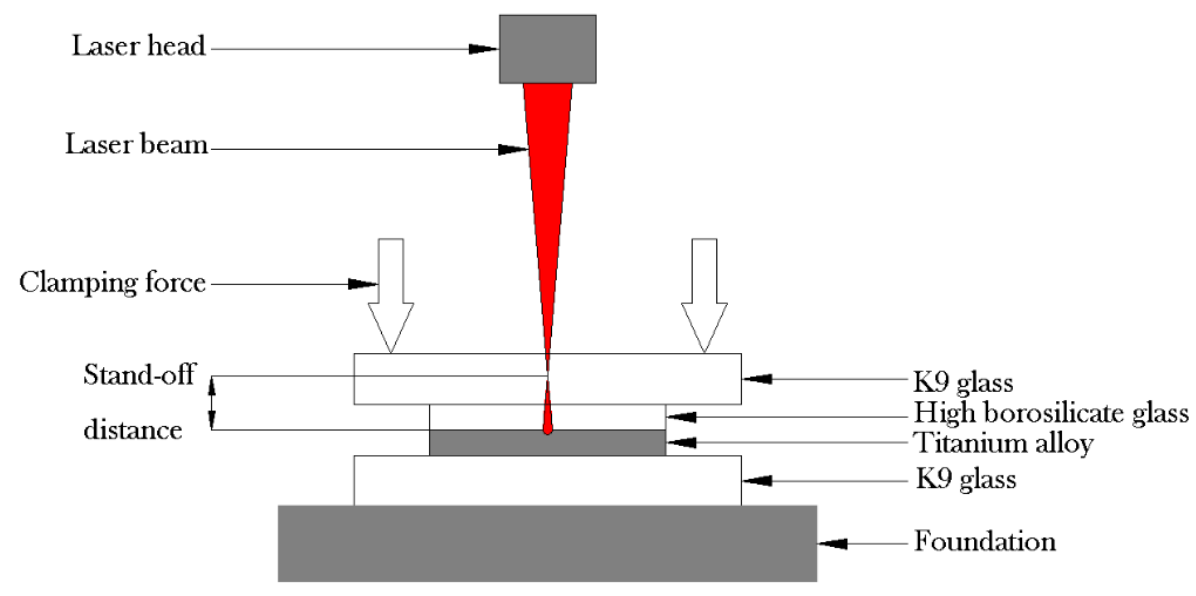

Figure 1. Laser transmission welding schematic.

Table 5. Process parameters and limits for laser transmission welding.

\begin{tabular}{ccccc}
\hline Parameter & \multicolumn{4}{c}{ Limits } \\
\hline Laser voltage for transmission welding $(\mathrm{W})$ & 450 & 460 & 470 & 480 \\
Laser welding speed $(\mathrm{mm} / \mathrm{s})$ & 3 & 3 & 3 & 3 \\
Laser frequency $(\mathrm{Hz})$ & 10 & 10 & 10 & 10 \\
Laser pulse width $(\mathrm{ms})$ & 2.5 & 2.5 & 2.5 & 2.5 \\
Stand-off distance $(\mathrm{mm})$ & 0 & 0 & 0 & 0 \\
\hline
\end{tabular}

A universal tensile machine (UTM4104, Shenzhen Suns Technology Co., Ltd., Shenzhen, China) was used for testing the joint strength, with $\mathrm{v}=2 \mathrm{~mm} / \mathrm{min}$. The lap shearing test finally broke the joints through loading tension at both ends of the joints. In this paper, the joint strength is measured by shear stress, and the shear stress is calculated as Formula (1):

$$
\sigma=\frac{F}{W \times L}
$$

An ultra-depth optical microscopy (VHX-1000, Keyence Corporation, Osaka, Japan) was used to observe the micromorphology of the joint. The interface elemental diffusion analysis was performed using a scanning electron microscope (S-3400N, Hitachi Corporation, Tokyo, Japan).

The contact angle was measured using a contact-angle measurement (OCA40, Dataphysics Instruments $\mathrm{GmbH}$, Stuttgart, Germany). The surface free energy of the material was calculated using the method of Ownes [22]. The surface free energy $(\gamma)$ is taken into account the polar components $\left(\gamma^{P}\right)$ and dispersive components $\left(\gamma^{D}\right)$, and needs to use two test liquids. In this study, pure water and ethylene glycol were used as test liquids. The relevant formulas are shown below [23]:

$$
\begin{gathered}
\gamma=\gamma^{D}+\gamma^{P} \\
\left.\gamma_{l 1}\left(1+\cos \theta_{1}\right)=2\left[\left(\gamma_{l 1}^{D} \gamma_{s}^{D}\right)^{0.5}+\gamma_{l 1}^{P} \gamma_{s}^{P}\right)^{0.5}\right] \\
\left.\gamma_{l 2}\left(1+\cos \theta_{2}\right)=2\left[\left(\gamma_{l 2}^{D} \gamma_{s}^{D}\right)^{0.5}+\gamma_{l 2}^{P} \gamma_{s}^{P}\right)^{0.5}\right]
\end{gathered}
$$

where $\gamma_{l 1}$ is the surface tension of pure water $\left(\gamma_{l 1}=75 \mathrm{mN} / \mathrm{m}\right) ; \gamma_{l 2}$ is the surface tension of ethylene glycol $\left(\gamma_{l 2}=48 \mathrm{mN} / \mathrm{m}\right) ; \theta_{1}$ represents the surface contact angle of pure water; $\theta_{2}$ represents the surface contact angle of ethylene glycol; $\gamma_{l 1}^{D}$ and $\gamma_{l 2}^{D}$ are the dispersive components of the surface tension of pure water and ethylene glycol, respectively $\left(\gamma_{l 1}^{D}=21.6 \mathrm{mN} / \mathrm{m}, \gamma_{l 2}^{D}=29 \mathrm{mN} / \mathrm{m}\right)$; and $\gamma_{l 1}^{P}$ and $\gamma_{l 2}^{P}$ represent the polar components of the surface tension of pure water and ethylene glycol, respectively $\left(\gamma_{l 1}^{P}=53.4 \mathrm{mN} / \mathrm{m}, \gamma_{l 2}^{P}=19 \mathrm{mN} / \mathrm{m}\right)$. 


\section{Results and Discussion}

\subsection{Effect of Laser Surface Treatment on Welding Strength}

Figure 2 shows the surface morphology of the titanium alloy after laser oxidation treatment with a spot diameter of $2 \mathrm{~mm}$, a scanning speed of $5 \mathrm{~mm} / \mathrm{s}$, a number of scans of 8 , and laser surface treatment powers of 40,50, and $60 \mathrm{~W}$. When the laser surface treatment power was $50 \mathrm{~W}$, the surface treatment was achieved with no obvious occurrence of melt, and the oxide layer was also formed.

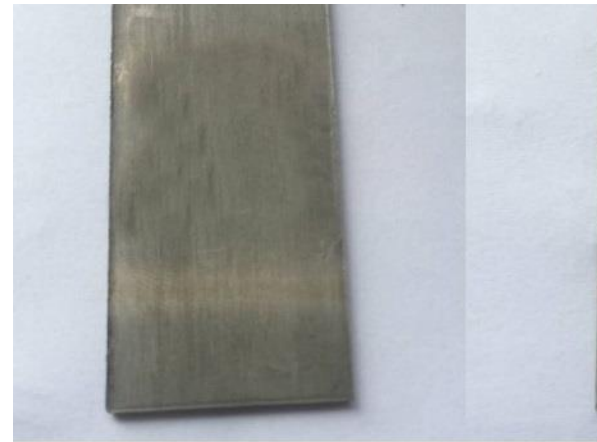

(a)

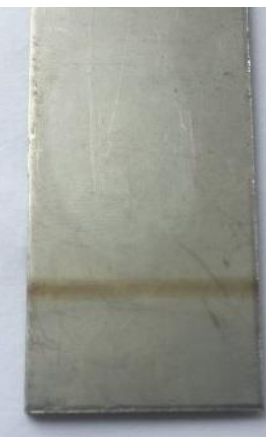

(b)

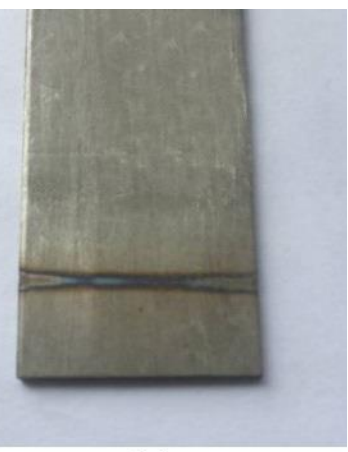

(c)

Figure 2. Surface morphology of titanium alloy after treatment by surface treatment power (a) 40, (b) 50 , and (c) $60 \mathrm{~W}$.

The laser transmission welding of titanium alloy without laser surface treatment with glass was carried out first. It was found that the welding strength was only $1.31 \mathrm{MPa}$ when the welding speed was $3 \mathrm{~mm} / \mathrm{s}$ with a laser voltage of $460 \mathrm{~V}$, a laser frequency of $10 \mathrm{~Hz}$, a laser pulse width of $2.5 \mathrm{~ms}$, and a defocusing amount of $0 \mathrm{~mm}$. Figure 3 shows the effect of laser surface treatment power $(45,50$, and $55 \mathrm{~W}$ ) on welding strength.

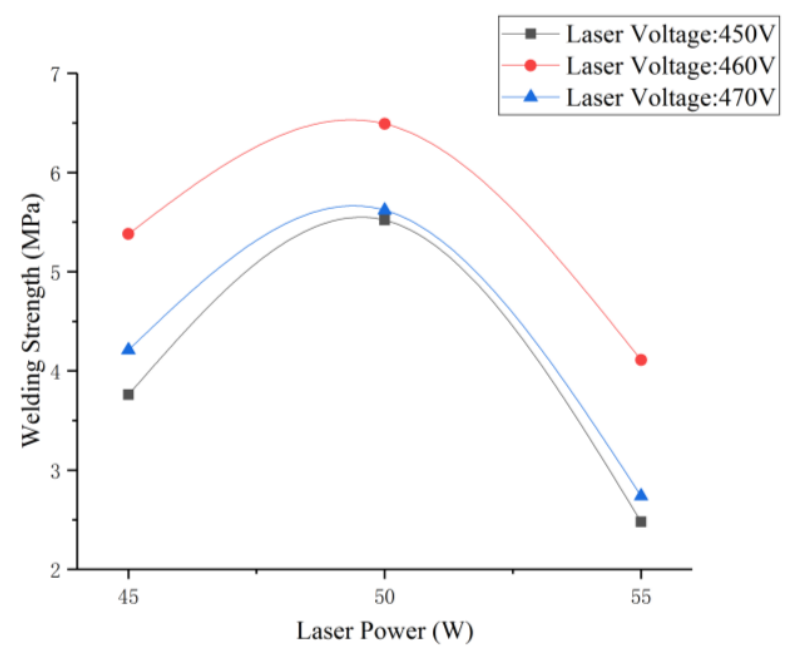

Figure 3. Effect of laser surface treatment power on welding strength.

As shown in the Figure 4, when the laser surface treatment power was $50 \mathrm{~W}$, the laser voltage for transmission welding was $460 \mathrm{~V}$, the welding speed was $3 \mathrm{~mm} / \mathrm{s}$, the laser frequency was $10 \mathrm{~Hz}$, the laser pulse width was $2.5 \mathrm{~ms}$, and the defocusing amount was $0 \mathrm{~mm}$, the welding strength was the highest $(6.49 \mathrm{MPa})$, which was 5 times that of the welding strength without laser surface treatment. Figure 4 shows the sample of laser transmission welding between titanium alloy and high borosilicate glass. It was found that the oxide film formed on the surface of the titanium alloy had a tendency 
to adhere to the high borosilicate glass [24], which is favorable for the improvement of the laser transmission welding strength.

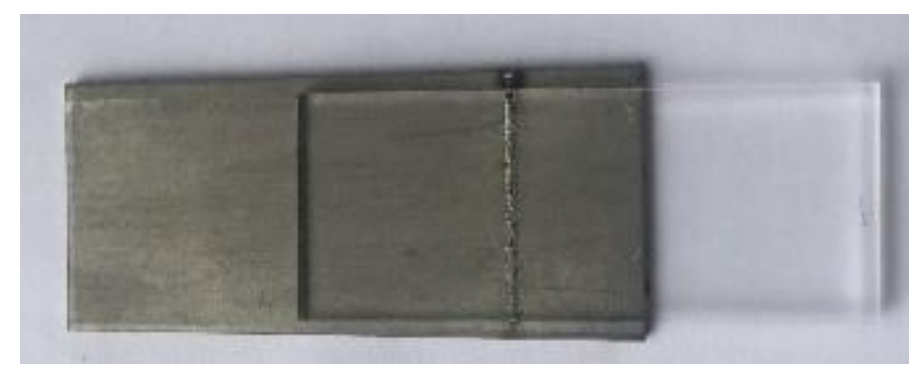

Figure 4. Welding between titanium alloy and high borosilicate glass.

\subsection{Micromorphology of Welding Seam and Tensile Failure Analysis}

An ultra-depth optical microscopy was used to observe the micromorphology of welding seam after tensile test. Figure 5 shows the micrographs of titanium alloy and high borosilicate glass welds after tensile test with $100 \times$. Under high temperature, the laser treated titanium alloy chemically reacted with $\mathrm{SiO}_{2}$ in the glass and formed black adherents. These black adherents differed from the initial glass form and were relatively firmly attached to the glass, forming a small-size interlock effect.
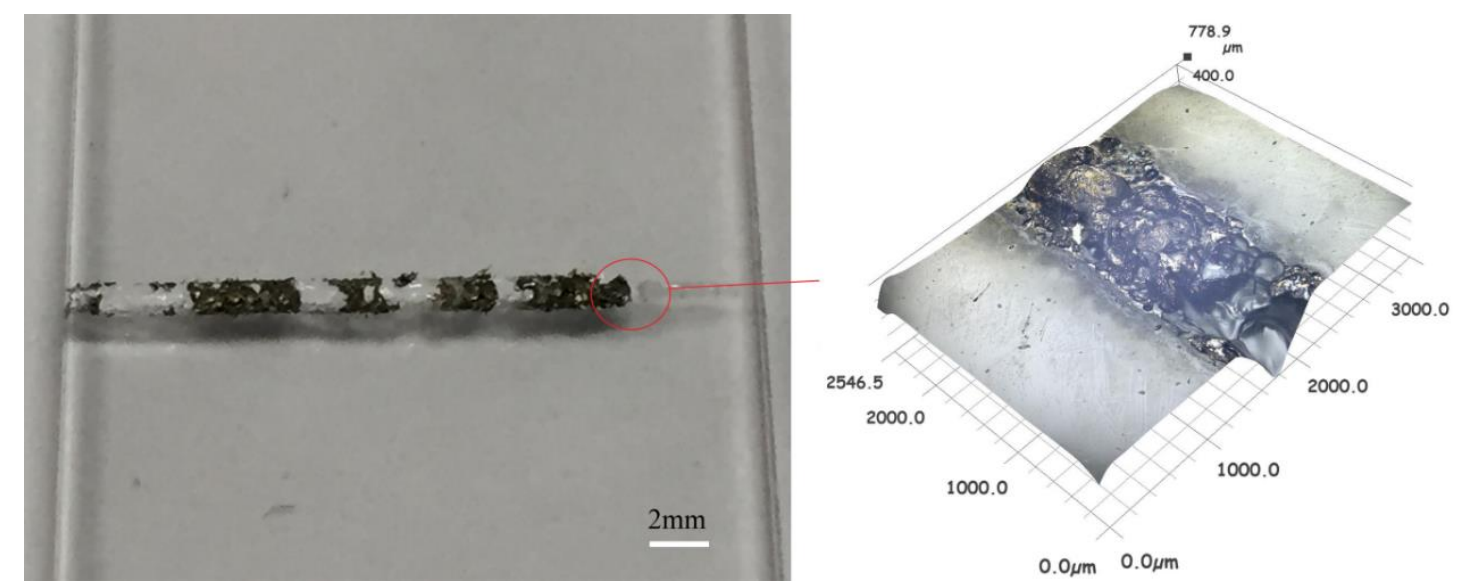

(a)
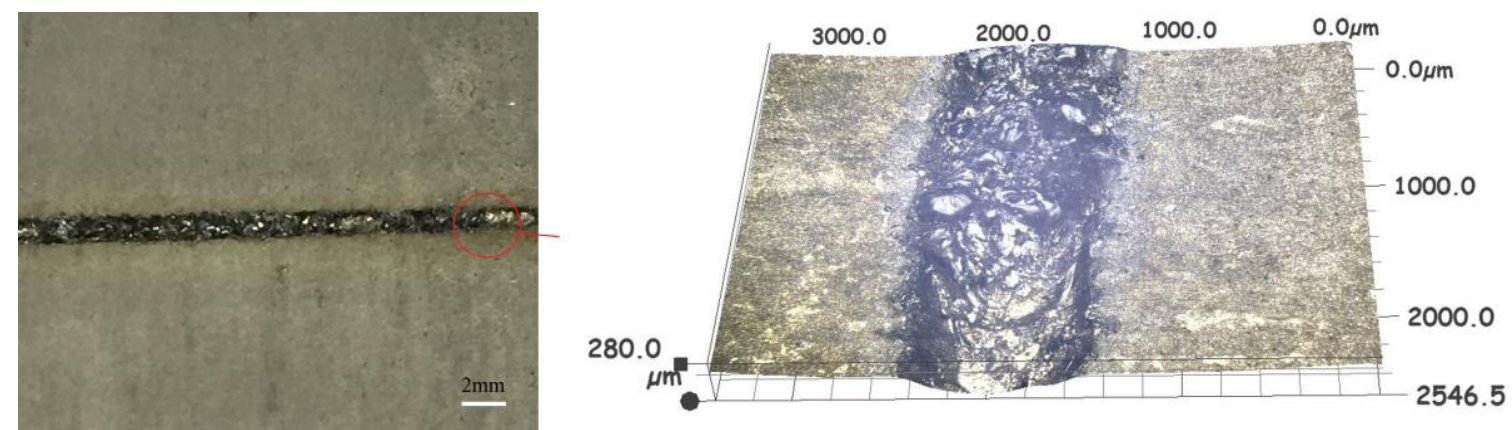

(b)

Figure 5. Micrographs of titanium alloy and high-borate borosilicate glass welds after tensile test:

(a) glass and (b) titanium alloy.

When the laser surface treatment power was $50 \mathrm{~W}$, the welding speed was $3 \mathrm{~mm} / \mathrm{s}$, the laser frequency was $10 \mathrm{~Hz}$, the pulse width was $2.5 \mathrm{~ms}$, the defocusing amount was $0 \mathrm{~mm}$, and the laser voltages for transmission welding were 440,460 , and $480 \mathrm{~V}$; the welding strengths obtained were 5.52, 
6.49, and 5.62 MPa, respectively. The morphologies of the welds after tensile fracture are presented in Figures 6-8.

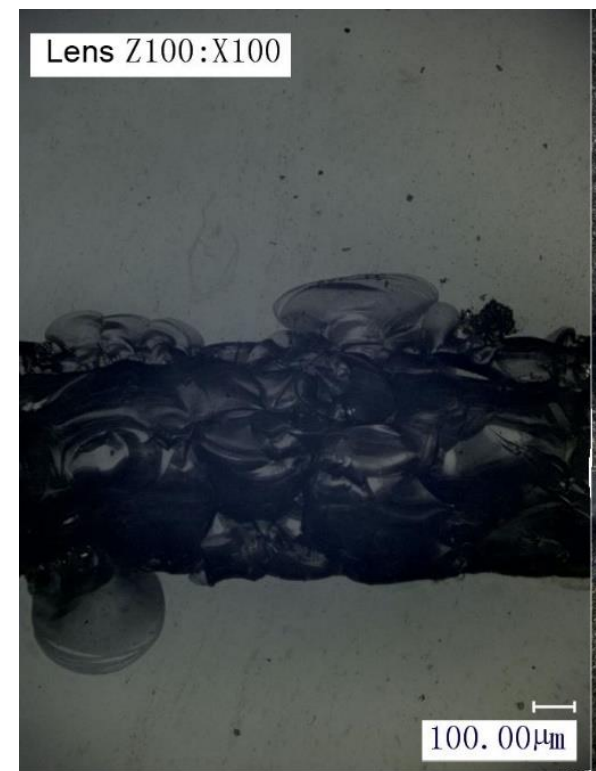

(a)

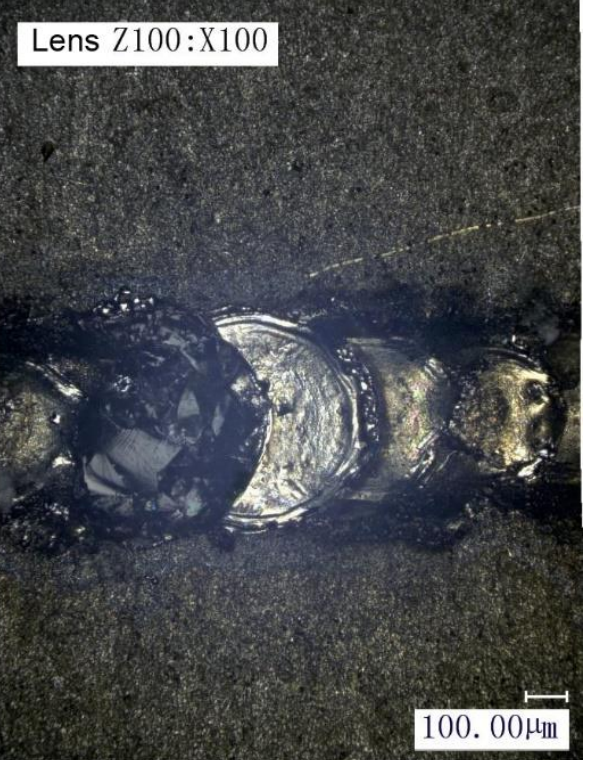

(b)

Figure 6. Micrographs of titanium alloy and high borosilicate glass using laser voltage for transmission welding of $440 \mathrm{~V}$ : (a) glass and (b) titanium alloy.

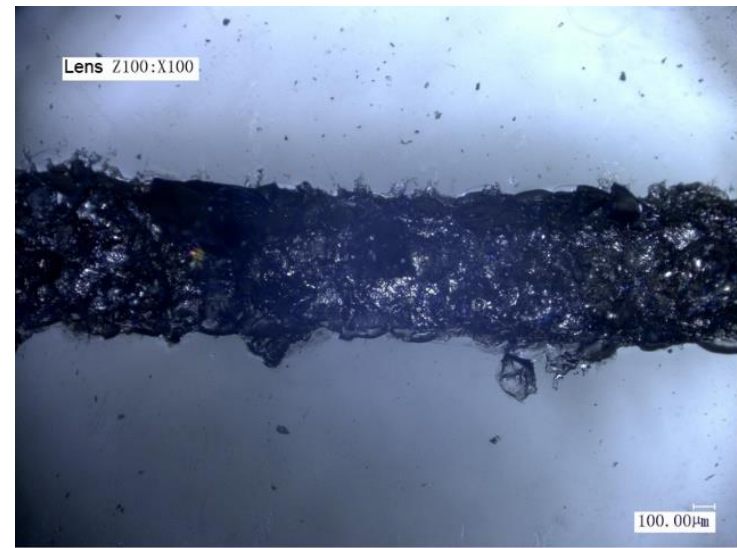

(a)

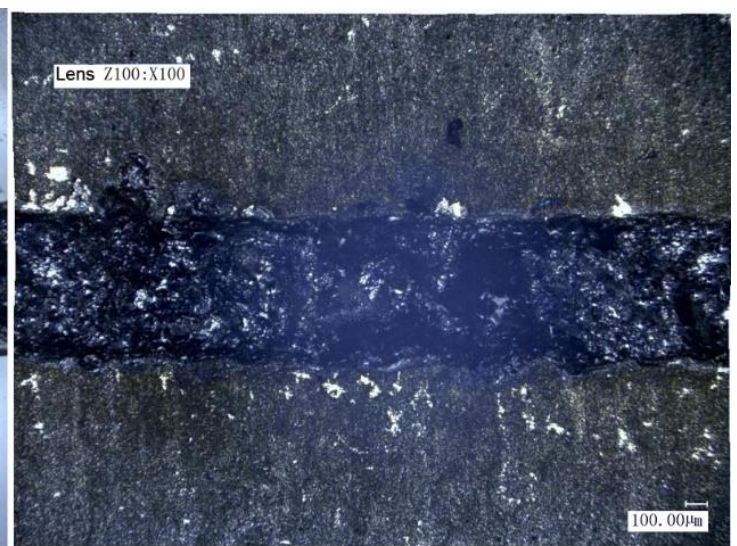

(b)

Figure 7. Micrographs of titanium alloy and high borosilicate glass using laser voltage for transmission welding of $460 \mathrm{~V}$ : (a) glass and (b) titanium alloy.

It can be seen from Figure 6 that when the laser voltage for transmission welding was $440 \mathrm{~V}$, no adherent was formed at the welding seam. This is because the laser voltage was small and the energy input was insufficient. Although droplets were splashed on the surface of the titanium alloy, they did not have a sufficient chemical reaction with the glass. A row of concave structures were only formed on the surface of the titanium alloy, resulting in un-ideal welding.

The welding seam of the titanium alloy and the glass was uniform and aesthetic when the laser voltage for transmission welding was $460 \mathrm{~V}$, as shown in Figure 7. When magnified $500 \times$, a dimple structure at the welding interface between the titanium alloy and the glass was observed [25] and indicating that a good weld existed between the titanium alloy and the glass, as shown in Figure 9. 


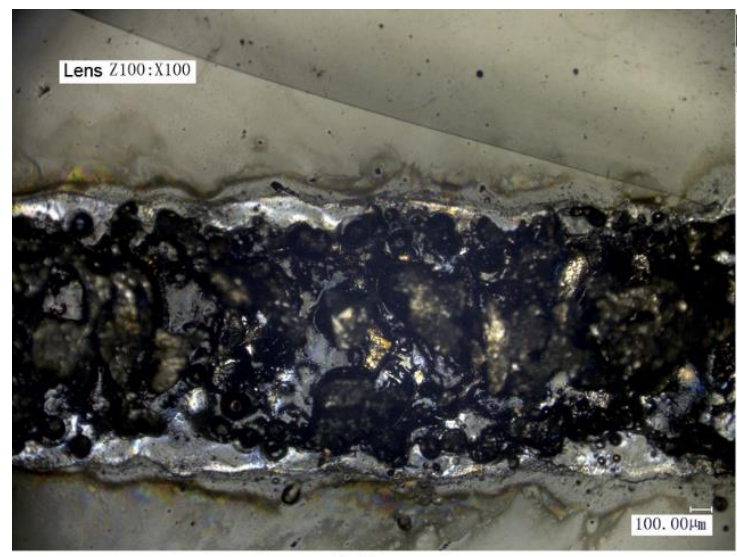

(a)

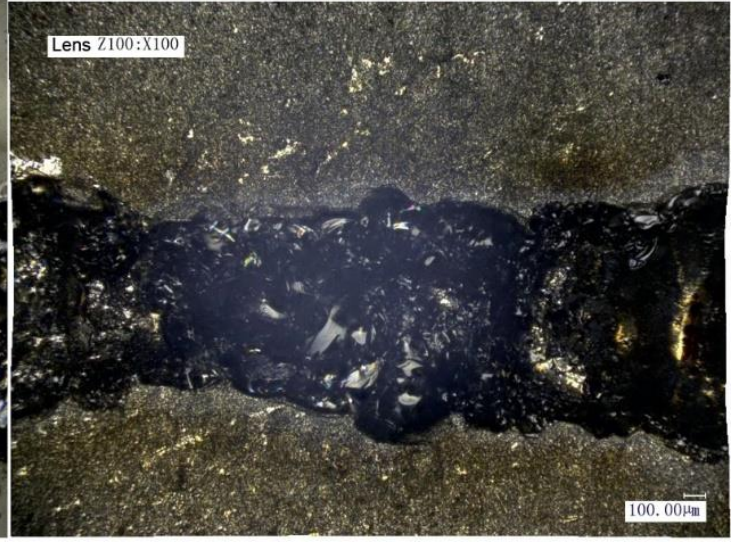

(b)

Figure 8. Micrographs of titanium alloy and high borosilicate glass using laser voltage for transmission welding of $480 \mathrm{~V}$ : (a) glass and (b) titanium alloy.

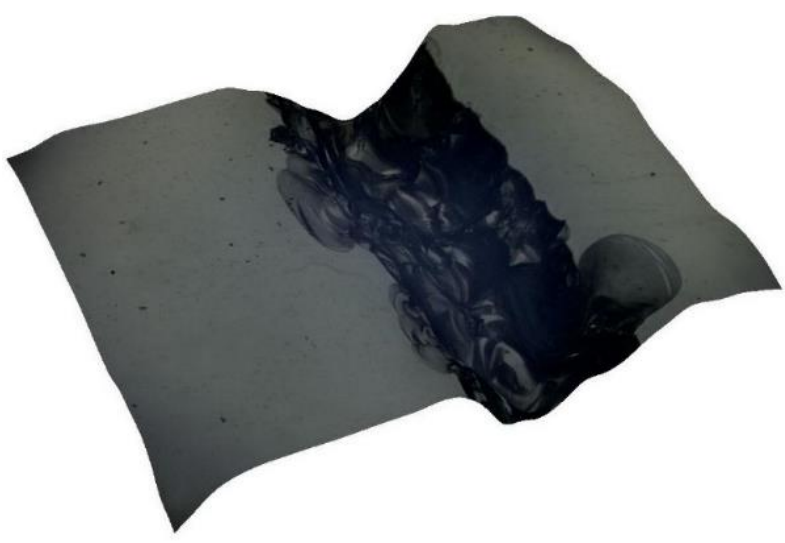

(a)

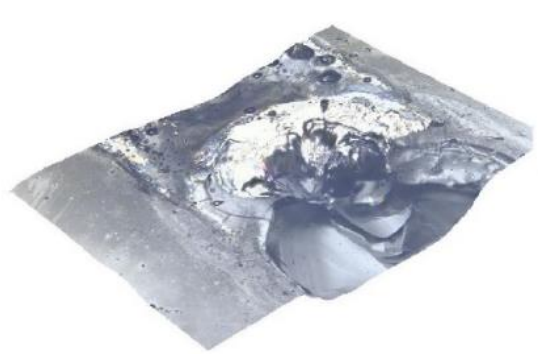

(b)

Figure 9. Micrographs of the weld at 500×: (a) glass and (b) titanium alloy.

It can be seen from Figure 8 that when the laser voltage for transmission welding was $480 \mathrm{~V}$, there were slight breakages and obvious cracks at the glass weld, and ablation occurred at the weld of the titanium alloy. The heat and impact generated by the pulsed laser resulted in a brittle failure on the glass, which seriously affects the weld and the welding strength.

Figure 10 shows the changes of tensile load as a function of time in a tensile test recorded by a UTM4104 universal testing machine. It can be seen from Figure 10a that when the laser voltage for transmission was $440 \mathrm{~V}$, uniform relative movement occurred to the titanium alloy and glass with the testing machine, which had a uniform linear motion, until the breaking force reached the maximum value, at which time the relative displacements of the titanium alloy and glass were small. Since the fracture of the weld is flush and bright, and perpendicular to the direction of the normal stress, the fracture failure mode is mainly brittle fracture. 


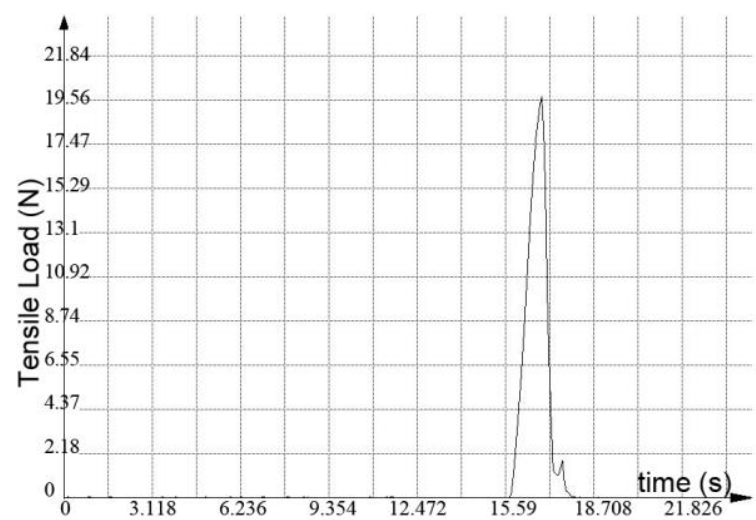

(a)

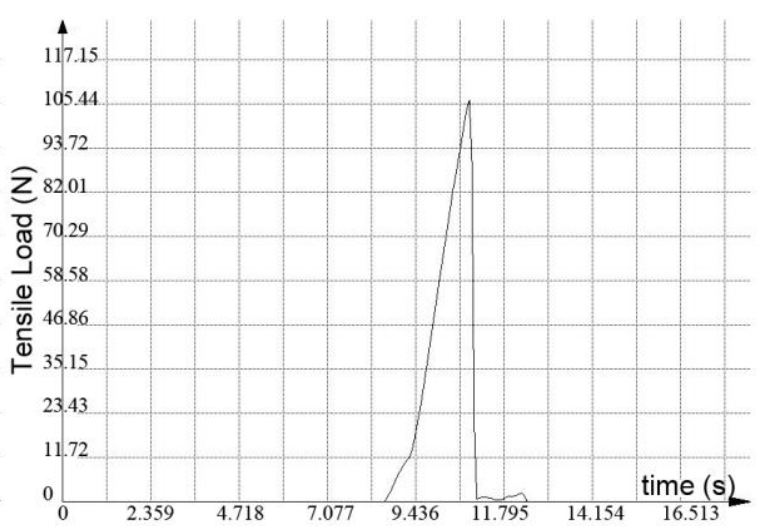

(b)

Figure 10. Tensile load changes with time at laser voltages for transmission welding of (a) 440 and (b) $460 \mathrm{~V}$.

It can be seen from Figure $10 \mathrm{~b}$ that when the laser voltage for transmission welding was 460 $\mathrm{V}$, the maximum value of the breaking force was reached after a certain displacement between the titanium alloy and the glass was formed, when they moved with the testing machine, which has a uniform linear motion. The adherents after fracture were observed at the weld fracture, which indicates that a good weld was achieved between the titanium alloy and the glass, and the failure form is mainly ductile fracture.

\subsection{Diffusion of Elements at the Joint Interface}

In order to further explore the mechanism for the formation of welded joints between titanium alloy with high-borate borosilicate glass during laser transmission welding, the cross-section morphology of the sample was observed by an S-3400N scanning electron microscope. The joint interface of the weld was investigated with an X-ray energy spectrometer for elemental-line scanning analysis to obtain the chemical composition in the weld (Figure 11).

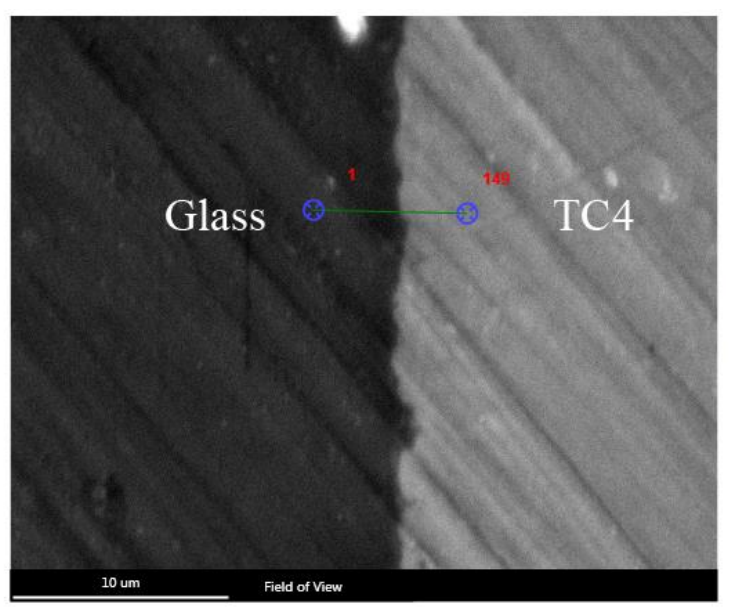

(a)

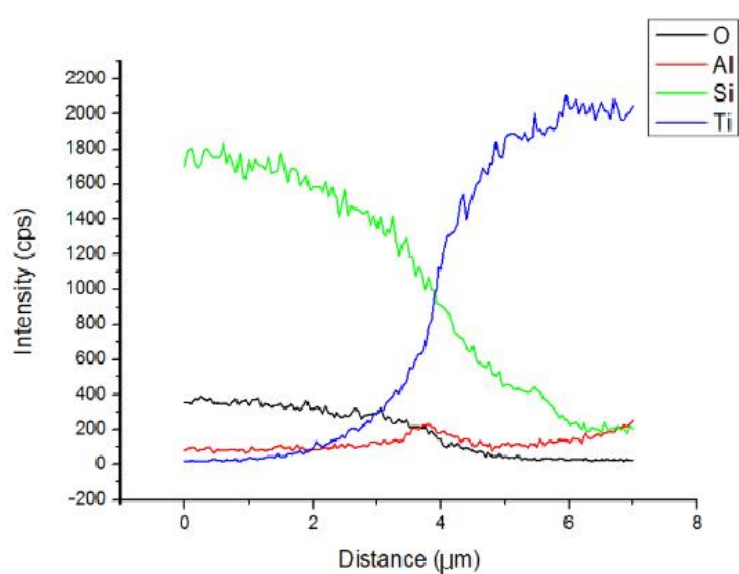

(b)

Figure 11. Scanning-electron-microscope (a) micrographs of cross-section and (b) element distribution along scan line.

The green and blue lines in Figure 11 represent the changes in the content of Si and Ti, respectively. There was a weak inter-diffusion between elemental Si and Ti at the joint interface. The thickness of the diffusion transition layer was approximately $4 \mu \mathrm{m}$. Under laser pulses impact, obvious elemental diffusion phenomenon occurred between the glass and titanium alloy, which is an important reason for the formation of high-strength welded joints. 


\subsection{Contact Angle and Surface Energy}

The surface contact angle is the angle between the tangent of the droplet profile and the solid surface it contacts, and it is an important indicator of the wettability of solid surfaces [26]. If $\theta<90^{\circ}$, the solid surface is hydrophilic, and the smaller the contact angle, the better the wettability. If $\theta>90^{\circ}$, the solid surface is hydrophobic, and the liquid does not wet the solid easily, but will move on the surface easily.

The surface contact angles of the titanium alloy with and without laser surface treatment were separately measured by a CA040 surface contact angle measurement, and are shown in Figures 12 and 13 , respectively.

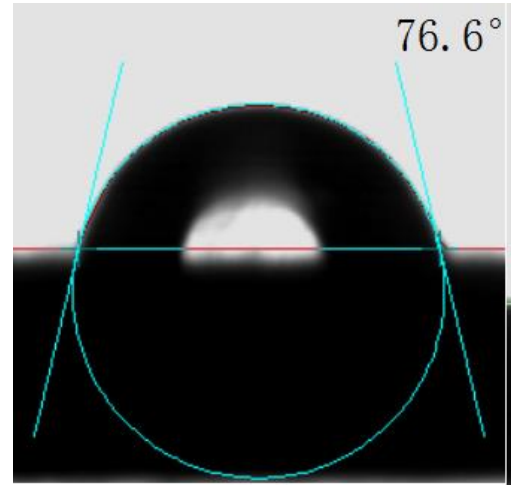

(a)

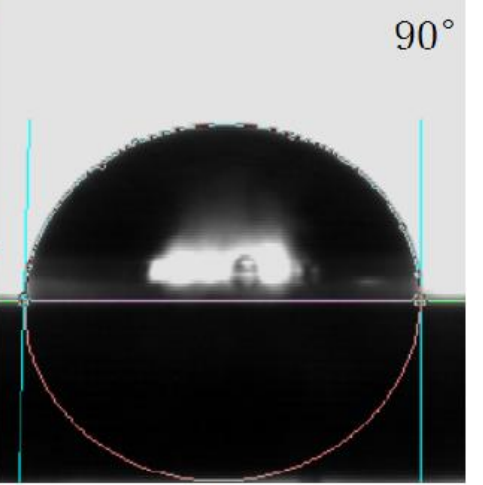

(b)

Figure 12. Water contact angle of titanium alloy (a) with an (b) without laser treatment.

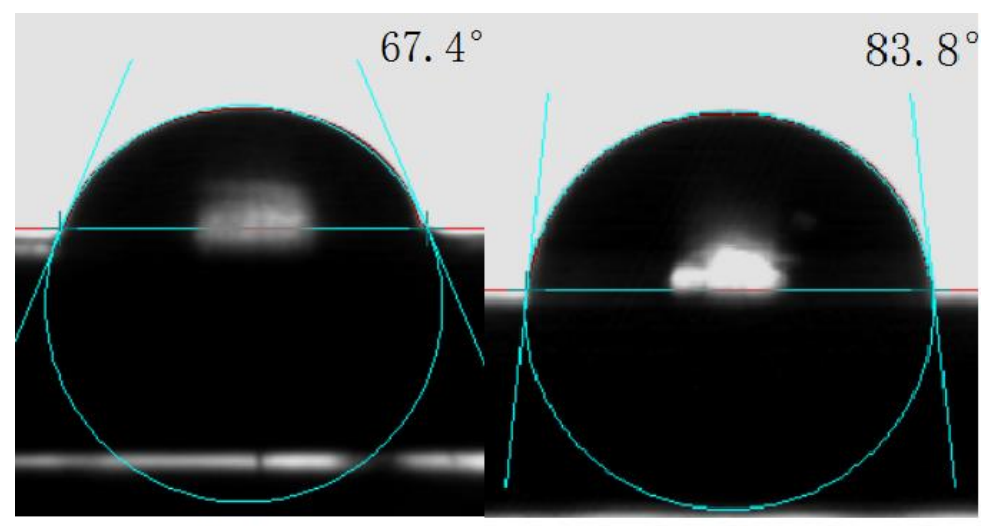

(a)

(b)

Figure 13. Ethylene glycol contact angle of titanium alloy (a) with and (b) without laser treatment.

As can be seen from Figures 12 and 13, the surface contact angle of the titanium alloy after laser surface treatment decreased and the wettability improved. The surface free energy of the titanium alloy before and after laser surface treatment was calculated using Equations (3) and (4); the results are shown in Table 6. The surface energy of the titanium alloy increased after laser surface treatment, which promoted the compatibility between the titanium alloy and the glass, thus improving the welding strength during laser transmission welding.

Table 6. Surface free energies of titanium alloy.

\begin{tabular}{cccc}
\hline Material Type & $\gamma(\mathrm{mN} / \mathrm{m})$ & $\gamma^{D}(\mathrm{mN} / \mathrm{m})$ & $\gamma^{P}(\mathrm{mN} / \mathrm{m})$ \\
\hline Titanium alloy & 19.31 & 16.45 & 2.86 \\
Laser-treated & 23.60 & 22.01 & 1.6 \\
\hline
\end{tabular}


Other researchers have also shown that the surface free energy of materials is an important factor affecting the welding strength when they were studying laser transmission welding. For example, Liu et al. investigated the laser transmission welding of PA66 with PVC [27]. It was found that the surface free energy of PA66 after surface magnetron sputtering of a layer of Al increased, so that PA66 and PVC, which could not be welded originally, were welded, forming a reliable connector through laser transmission welding by using $\mathrm{Al}$ atoms as a transition layer. This indicates that the increase of the material's surface free energy is beneficial to improving the strength of the joint.

\section{Conclusions}

The laser transmission welding of high borosilicate glass with titanium alloy was conducted. It was found that the welding strength could be improved by laser surface treatment of the titanium alloy. The joining mechanism was studied by the morphology, tensile-fracture mode, the elements diffusion, the surface free energy, and the following conclusions were drawn.

(1) A large number of black adherents were observed at the weld between the laser-surface-treated titanium alloy and the high borosilicate glass. A small-size interlock effect may be formed, resulting in a strong joining effect;

(2) The welding strength was the higher when the laser voltage for transmission welding was $460 \mathrm{~V}$, and the tensile-fracture failure mode was mainly ductile fracture. When the voltage for transmission welding was high, the titanium alloy was ablated due to excessive energy input, and the glass was cracked, thus reducing the welding strength;

(3) It was found that there was elemental diffusion at the weld interface between the titanium alloy and the glass, which is an important reason for the formation of high-strength welded joints;

(4) The measurement of the surface contact angles of the titanium alloy shows that the laser surface treatment of the titanium alloy increased the surface energy and promoted the compatibility between the titanium alloy and the glass, thus improving the welding strength of the two materials.

Author Contributions: Conceptualization, P.L. and H.L.; Methodology, X.W.; Software, W.T.; Validation, P.L., X.X. and W.T.; Formal Analysis, P.L. and X.X.; Investigation, P.L. and X.X.; Resources, H.L.; Data Curation, P.L.; Writing-Original Draft Preparation, P.L. and X.X.; Writing-Review \& Editing, P.L.; Visualization, P.L.; Supervision, X.W.; Project Administration, H.L.; Funding Acquisition, H.L.

Funding: This research was funded by [National Natural Science Foundation of China] grant number [No. 51275219] And The APC was funded by [National Natural Science Foundation of China] grant number [No. 51275219].

Acknowledgments: The authors acknowledge the National Natural Science Foundation of China (No. 51275219), and the Changzhou High-technology Research Key Laboratory (No. CM20153001).

Conflicts of Interest: The authors declare no conflict of interest.

\section{References}

1. Lei, D.; Wang, Z. The calculation and analysis of glass-to-metal sealing stress in solar absorber tube. Renew. Energy 2010, 35, 405-411. [CrossRef]

2. Leichtfried, G.; Thurner, G. Molybdenum alloys for glass-to-metal seals. Int. J. Refract. Met. Hard Mater. 1998, 16, 13-22. [CrossRef]

3. Lei, D.; Wang, Z. Experimental study of glass to metal seals for parabolic trough receivers. Renew. Energy 2012, 48, 85-91. [CrossRef]

4. Butkus, S.; Paipulas, D. Improvement of Cut Quality in Rapid-Cutting of Glass Method via Femtosecond Laser Filamentation. J. Laser Micro Nanoeng. 2015, 10, 59-63. [CrossRef]

5. Athanasiou, C.E.; Hongler, M.O. Unraveling Brittle-Fracture Statistics from Intermittent Patterns Formed During Femtosecond Laser Exposure. Phys. Rev. Appl. 2017, 8. [CrossRef]

6. Carter, R.M.; Troughton, M. Towards industrial ultrafast laser microwelding: $\mathrm{SiO}_{2}$ and $\mathrm{BK} 7$ to aluminum alloy. Appl. Opt. 2017, 56, 4873-4881. [CrossRef] [PubMed] 
7. Volpe, A.; Di Niso, F. Welding of PMMA by a femtosecond fiber laser. Opt. Express 2015, 23, 4114-4124. [CrossRef] [PubMed]

8. Richter, S.; Doering, S. Bonding of glass with femtosecond laser pulses at high repetition rates. Appl. Phys. A 2011, 103, 257-261. [CrossRef]

9. Itoh, K.; Tamaki, T. Ultrafast laser microwelding for transparent and heterogeneous materials. In Proceedings of the Commercial and Biomedical Applications of Ultrafast Lasers VIII, San Jose, CA, USA, 20-23 January 2008; Volume 6881.

10. Utsumi, A.; Ooie, T. Direct Bonding of Glass and Metal Using Short Pulsed Laser. J. Laser Micro Nanoeng. 2007, 2, 133-136. [CrossRef]

11. Quintino, L.; Liu, L. Bonding NiTi to glass with femtosecond laser pulses. Mater. Lett. 2013, 98, $142-145$. [CrossRef]

12. Flury, M.; Pedri, C. Laser Induced Reverse Transfer with metal and hybrid material prepared with sol-gel process used on glass substrate. Appl. Surf. Sci. 2013, 278, 142-145. [CrossRef]

13. Ciuca, O.P.; Carter, R.M. Characterisation of weld zone reactions in dissimilar glass-to-aluminium pulsed picosecond laser welds. Mater. Charact. 2016, 120, 53-62. [CrossRef]

14. Carter, R.M.; Chen, J. Picosecond laser welding of similar and dissimilar materials. Appl. Opt. 2014, 53, 4233-4238. [CrossRef] [PubMed]

15. Lin, H.K.; Hong, S.Z. Characterization of local laser bonding quartz to anodic aluminum oxide in light emission device. Opt. Quantum Electron. 2017, 49. [CrossRef]

16. Caccia, M.; Rodriguez, A. Diamond Surface Modification to Enhance Interfacial Thermal Conductivity in Al/Diamond Composites. JOM 2014, 66. [CrossRef]

17. Molina, J.-M.; Rodríguez-Guerrero, A.; Louis, E.; Rodríguez-Reinoso, F.; Narciso, J. Porosity Effect on Thermal Properties of Al-12 wt \% Si/Graphite Composites. Materials 2017, 10, 177. [CrossRef] [PubMed]

18. Chern, T.-S.; Tsai, H.-L. Wetting and sealing of interface between 7056 Glass and Kovar alloy. Mater. Chem. Phys. 2007, 104, 472-478. [CrossRef]

19. Zhang, M.; Yao, Y.L. Effects of Laser Radiation on the Wetting and Diffusion Characteristics of Kovar Alloy on Borosilicate Glass. J. Manuf. Sci. Eng. 2018, 140. [CrossRef]

20. Li, P.; Li, J. Experimental Study on the Laser Transmission Joining of Polystyrene and Titanium. Materials 2018, 11, 1513. [CrossRef] [PubMed]

21. Wang, X.; Li, P. Laser transmission joint between PET and titanium for biomedical application. J. Mater. Process. Technol. 2010, 210, 1767-1771. [CrossRef]

22. Owens, D.K.; Wendt, R.C. Estimation of the surface free energy of polymers. J. Appl. Polym. Sci. 1969, 13, 1741-1747. [CrossRef]

23. Schrader, M.E.; Loeb, G.I. Modern Approaches to Wettability: Theory and Applications; Springer: New York, NY, USA, 1992.

24. Baldan, A. Adhesively-bonded joints and repairs in metallic alloys, polymers and composite materials: Adhesives, adhesion theories and surface pretreatment. J. Mater. Sci. 2004, 39, 1-49. [CrossRef]

25. Liu, F.C.; Liao, J. Joining of metal to plastic using friction lap welding. Mater. Des. 2014, 54, $236-244$. [CrossRef]

26. Ochoa-Putman, C.; Vaidya, U.K. Mechanisms of interfacial adhesion in metal-polymer composites-Effect of chemical treatment. Compos. Part A Appl. Sci. Manuf. 2011, 42, 906-915. [CrossRef]

27. Liu, H.; Chen, G. Performance and mechanism of laser transmission joining between glass fiber-reinforced PA66 and PC. J. Appl. Polym. Sci. 2016, 133. [CrossRef]

(C) 2018 by the authors. Licensee MDPI, Basel, Switzerland. This article is an open access article distributed under the terms and conditions of the Creative Commons Attribution (CC BY) license (http://creativecommons.org/licenses/by/4.0/). 